\title{
Economic performance evaluation of natural gas vehicles and their fuel infrastructures
}

\author{
Dejene A Hagos ${ }^{1, *}$ and Erik O Ahlgren ${ }^{1}$ \\ ${ }^{1}$ Department of Space, Earth and Environment, Chalmers University of Technology, SE-412 96 Göteborg, Sweden
}

\begin{abstract}
The transition from high carbon-intensity to low carbon-intensity transport fuels entails the development of energy efficient and cost-effective decarbonisation pathways. In this paper, 14 potential natural and renewable gas supply pathways and natural gas vehicles (NGVs) have been selected and evaluated with regards to well-to-tank (WTT) fuel production costs and break-even vehicle added investment costs. NGVs are evaluated for both road- and maritime transport applications with three types of gas engines; dedicated, dual fuel, and high pressure direct injection (HPDI) engines. The results indicate that owing to the alternate gas distribution mechanisms and filling stations configuration there exist a substantial fuel production cost differences between the selected gas pathways. Despite its long-distance shipping and distribution, imported LNG showed significant production cost advantage over compressed natural gas (CNG) and liquefied renewable natural gas (LRNG) pathways. Evaluating the current economic performances, all NGVs are found to be competitive corresponding to gasoline cars, but not compared to diesel cars due to the lower price gap between CNG and diesel. In the heavy-duty vehicle and passenger vessel segments, however, owing to the high price gap between LNG and diesel/marine gas oil (MGO), all NGVs and LNG passenger vessels showed high competitiveness compared to their conventional counterparts.
\end{abstract}

\section{Introduction}

In the last few decades, the transition to a low carbon economy and a green energy system have been a goal for many countries. The EU-27 countries reduced their combined total greenhouse gas (GHG) emissions during $1990-2014$ by $23 \%$. However, in the same period, the transport sector's emission increased by $20.1 \%$ [1]. Road transport took the greatest share, accounting for $73 \%$ of the total emission in 2014. This attributes to the higher emission mitigation costs of alternative transport systems. Efforts are being focused on the development of alternative fuel vehicles, improving vehicle power train system, and development of advanced vehicle fuels. As transition fuels, in recent decades, the use of natural gas (NG) and upgraded biogas or renewable natural gas (RNG) as vehicle fuels has become increasingly important. A high energy-to-carbon ratio, stable and low price, and abundant availability, and its clear burning characteristics makes NG an attractive alternative transport fuel. It could also potentially pave way for increased use of RNG. As a clear burning fuel, NG could also potentially reduce air pollutant emissions in urban areas. Nevertheless, its low energy density (which limits its driving range) and low cetane number (which restricts its use in compression engines without pilot diesel injection) are technical limitations. To increase its energy density and provide a longer driving range for NGVs, NG should either be compressed to about 200 bars and stored in high-pressure tanks (CNG), or cooled to $-162^{\circ} \mathrm{C}$ at atmospheric pressure and stored in highly insulated cryogenic tanks (LNG). Globally, as of 2016, NGVs make up $1.32 \%$ of the total vehicle population [2]. NGVs are widely used in Asia Pacific and Latin American countries. In Europe, few countries have shown high market penetration of NGVs, such as Italy and Germany [3].

In maritime transport applications, especially for short-range passenger ferries, LNG is becoming important as alternative to expensive low sulphur marine fuels to meet the tight emissions standard in emission control areas (ECA), such as Baltic Sea area [4]. As of 2015, globally, more than 70 LNG ships were in operation; mainly regional ferries located in Norway. Nevertheless, lack of bunkering standards and regulatory framework, reduced cargo space, methane leakage (during bunkering), methane slip (unburned methane), availability of bunkering ports, and high upfront vessel added investment cost are main challenges facing the market [5]. In this regard, assessment of the fuel

Corresponding author: dejene@chalmers.se 
WTT

\begin{tabular}{|c|c|c|c|c|c|}
\hline $\begin{array}{l}\text { Feedstock } \\
\text { extraction }\end{array}$ & $\begin{array}{c}\text { Feedstock } \\
\text { transportation }\end{array}$ & \begin{tabular}{|c|} 
Feedstock \\
conversion to fuel
\end{tabular} & \begin{tabular}{|l|} 
Transmission \\
and storage
\end{tabular} & Distribution & $\begin{array}{l}\text { Conditioning and } \\
\text { filling/bunkering }\end{array}$ \\
\hline
\end{tabular}

Figure 1. Major stages of the WTT cost evaluation.

production and conditioning costs of gas infrastructures and the added gas vehicle investment cost are critical to identify the true economic values of gas in transport, and for cost effective decarbonisation of the transport system at large. In most techno-economic modelling studies, due to the computational and modelling framework limitations, the detailed cost components of alternative fuels and vehicles often ignored or not properly captured. Thus, the aim of this study is to analyse the WTT fuel production and distribution costs of selected gas supply pathways and break-even added investment costs of gas vehicles, both for road transport application and maritime transport applications, within the Danish NG and RNG perspectives.

\section{Methodology}

In this section, the general approach, selected fuel supply pathways, the mode and types of gas vehicles included, and data sources and assumptions are discussed in brief.

\subsection{General approach}

The focus is on Denmark as a case. The assumed domestic feedstocks are the Danish NG mix (as of 2016), organic municipal waste, and cattle and pig manure, for biogas production. Figure 1 shows the major processes and stages of the evaluation, from feedstocks extraction to filling NGVs at filling stations and bunkering LNG passenger vessels at ports. The cost evaluations have been done using a model developed in Excel and comprise levelised fuel production costs at each stage, gas distribution costs to filling stations, and break-even added investment costs of NGVs. A general discount rate of $6 \%$ is assumed for all cases. The results of the levelised fuel production, distribution, and filling/bunkering costs estimations are reported in terms of $€ / G J$ (2016 price level).

The break-even added cost is the added investment cost of a gas vehicle over a similar conventional vehicle (in terms of engine brake power) at which the net present added cost equals the net present benefit of the gas vehicle due to the fuel cost savings over the analysis period. The net present value (NPV) is given as :

$N P V=\sum_{t=0}^{n} \frac{C_{N G V, t}}{(1+d)^{t}}-\sum_{t=0}^{n} \frac{C_{C V, t}}{(1+d)^{t}}$
At break-even, or no-loss no-profit point, NPV $=0$

$$
\begin{aligned}
& I C_{N G V}+\sum_{t=1}^{n} \frac{C_{N G V, t}}{(1+d)^{t}}=I C_{C V}+\sum_{t=1}^{n} \frac{C_{C V, t}}{(1+d)^{t}} \\
& I C_{N G V}-I C_{C V}=\sum_{t=1}^{n} \frac{C_{N G V, t}}{(1+d)^{t}}-\sum_{t=1}^{n} \frac{C_{C V, t}}{(1+d)^{t}}
\end{aligned}
$$

Where, $\mathrm{IC}_{\mathrm{NGV}}$ and $\mathrm{IC}_{\mathrm{CV}}$ refers to the investment costs of a specific $\mathrm{NGV}$ and the corresponding conventional vehicle, respectively while $\mathrm{C}_{\mathrm{NGV}}$ and $\mathrm{C}_{\mathrm{CV}}$ refers to the respective annual costs thereof, $\mathrm{d}$ refers to the assumed discount rate $(6 \%)$, and $t$ refers to the analysis period; assumed to be 13 years for cars, 7 years for HD vehicles, and 25 years for vessels.

The costs on the right-hand side include replacement costs, operation and maintenance costs, and salvage values, for each vehicle group. Then, the break-even added investment cost was calculated through an iterative process by varying the vehicle added cost $\left(\mathrm{IC}_{\mathrm{NGV}}-\mathrm{IC}_{\mathrm{CV}}\right)$ until the net present added cost equals to the net present benefit of the gas vehicle (due to fuel cost savings over the analysis period), or simply, when both sides cost components are equal. This is because some of the cost components like replacement cost and salvage value are dependent on the vehicle added cost.

\subsection{Selected fuel supply pathways}

The pathway selection has been done, mainly, based on the authors' preceding state-of-the art review. The pathways are primarily classified based on filling station configurations and gas distribution mechanisms. In the context of Danish gas infrastructures, the most probable pathways are generated. Figure 2 shows the three major blocks of pathways based on the filling station configurations; mother, daughter, and LNG/LRNG stations; mother stations are grid connected, and gas is transported to by pipeline while daughter stations are off grid, and $\mathrm{CNG}$ is transported to by $\mathrm{CNG}$ swap body/trailer. Within each block, the pathways are classified based on availability (private vs. public) and filling time (fast fill vs. time fill); the main difference between fast-fill ( 5 minutes) and time-fill (6-8 hours) stations is the availability of large-size storage and compressors and their cost. 

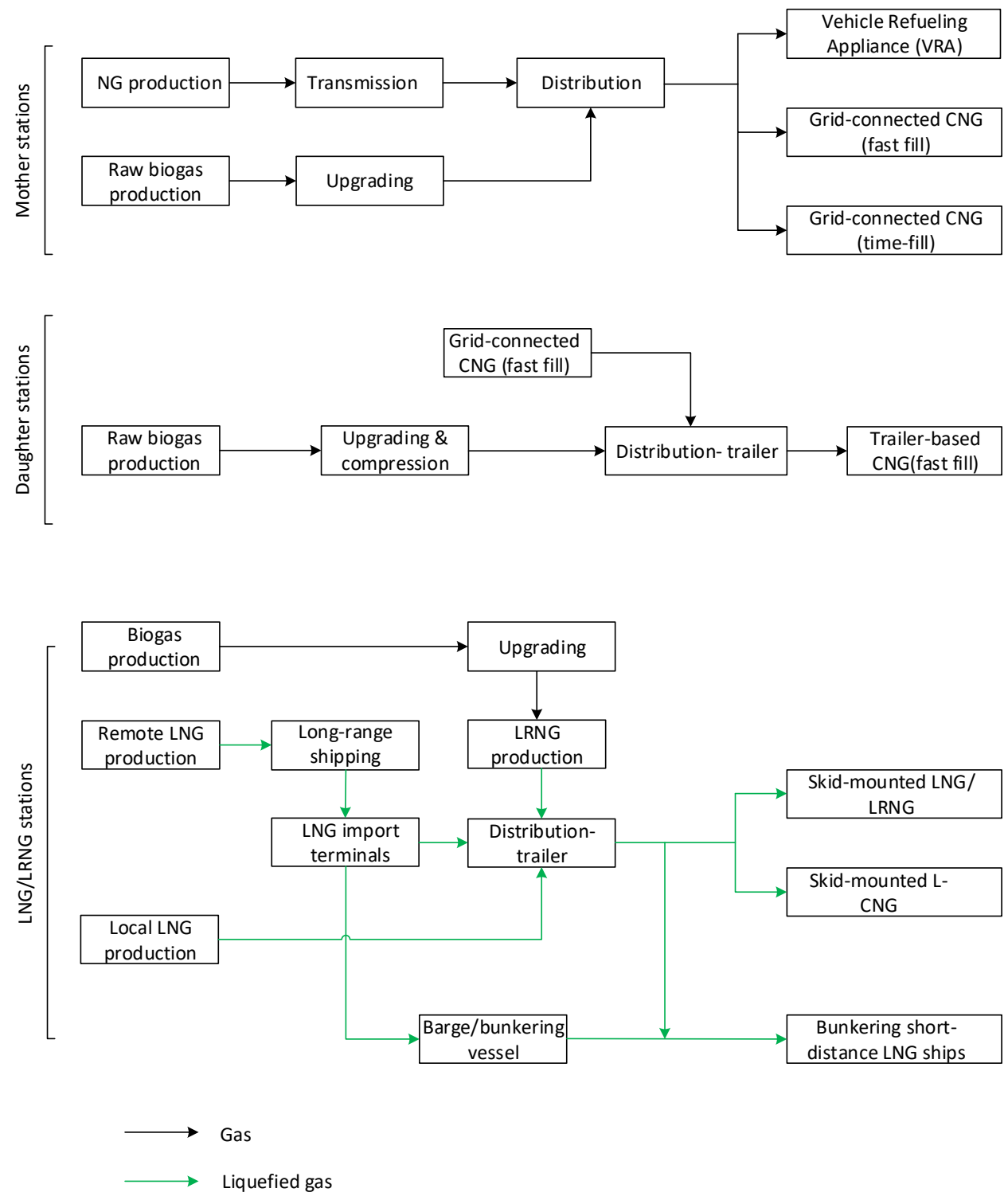

Figure 2. Schematic diagram of the processes and energy flows of potential gas supply pathways included in the WTT evaluation.

Then, based on figure 2 , a total of 14 pathways have been selected for cost evaluation as shown in table 1 (with their detailed descriptions and acronyms).

The mode of gas distribution to filling stations and bunkering ports are classed into four: a low-pressure (4 bar) polyethylene pipeline, CNG swap body/truck (4500 $\mathrm{Nm}^{3}$ capacity), LNG trailer $\left(60 \mathrm{~m}^{3}\right.$ capacity), and smallscale LNG carrier $\left(7500 \mathrm{~m}^{3}\right.$ capacity). Given the current practises, the one-way distance between loading and unloading terminals is assumed to be $1 \mathrm{~km}$ for pipeline, $50 \mathrm{~km}$ for $\mathrm{CNG} / \mathrm{CRNG}$ swap body/ truck, and $950 \mathrm{~km}$ for LNG trailer and LNG carrier vessel. Also, the filling stations capacity assumed to be $1300 \mathrm{~kg} /$ day for all cases, except for home filling or private stations, which is assumed to be $36 \mathrm{~kg} /$ day. The daily vessel bunkering capacity assumed to be $10 \mathrm{~m}^{3}$ per vessel. Pipeline cost functions (based on diameter, distance, and urban/rural share) [6], biogas plants investment costs [7, 8], LNG carrier/truck/trailer investment costs [6, 9], and filling station costs $[10,11]$ are taken from their respective sources and adjusted for 2016 price level using GDP deflators.

\subsection{Gas vehicles included}

The gas vehicles included in the evaluation are passenger (HDVs) for road-transport applications, and a short-range passenger vessel for maritime transport applications. The three state-of-the art gas engine technologies are port injection spark ignition (PISI), port injection dual-fuel (PIDF), and high pressure direct injection (HPDI) engines. The PISI gas engine works on $100 \%$ gas and Otto cycle, and it has a lower compression ratio and volumetric efficiency, and, thus, a lower cycle efficiency (about $35 \%$ ), compared to diesel engine [12]. 
Table 1. Selected pathways and process description.

\begin{tabular}{|c|c|c|c|}
\hline Type & Pathway acronym & Final fuel & Pathway description \\
\hline \multirow{3}{*}{$\begin{array}{l}\text { Mother } \\
\text { stations }\end{array}$} & VRA & $\mathrm{CNG}$ & $\begin{array}{l}\text { Danish NG mix, distributed through transmission and distribution pipes to } \\
\text { grid-connected households/industries. The home-filling facility, called vehicle } \\
\text { refuelling appliance (VRA), is assumed to be supplied with a low-pressure grid } \\
\text { ( } 4 \text { bar). }\end{array}$ \\
\hline & $\begin{array}{l}\text { CNGMF } \\
\text { CNGMT }\end{array}$ & $\mathrm{CNG}$ & $\begin{array}{l}\text { Danish NG mix, distributed through transmission and distribution pipes to } \\
\text { grid-connected filling stations. The station could be either a fast-fill (CNGMF) } \\
\text { or time-fill (CNGMT) station connected with a low-pressure grid. }\end{array}$ \\
\hline & $\begin{array}{l}\text { CRNGP-waste } \\
\text { CRNGP-manure }\end{array}$ & CRNG & $\begin{array}{l}\text { Raw biogas production from municipal organic waste (CRNGP-waste) and } \\
\text { manure (CRNGP-manure), upgrading, and injection into the low-pressure grid } \\
\text { ( } 4 \text { bar) through plastic pipes. }\end{array}$ \\
\hline \multirow{2}{*}{$\begin{array}{l}\text { Daughter } \\
\text { stations }\end{array}$} & CNGD & $\mathrm{CNG}$ & $\begin{array}{l}\text { The same process description as CNGMF pathway, but it represents daughter } \\
\text { stations. CNG supplied to the station is assumed to be filled at mother station } \\
\text { and transported with truck/CNG trailer. }\end{array}$ \\
\hline & $\begin{array}{l}\text { CRNGD-waste } \\
\text { CRNGD-manure }\end{array}$ & CRNG & $\begin{array}{l}\text { Raw biogas production from municipal organic waste (CRNGD-waste) and } \\
\text { manure (CRNGD-manure), upgrading and compression to } 200 \text { bar, and } \\
\text { truck/CNG trailer distribution to fast-fill CNG filling station. }\end{array}$ \\
\hline \multirow{6}{*}{$\begin{array}{l}\text { LNG/LRNG } \\
\text { stations }\end{array}$} & LNG & LNG & $\begin{array}{l}\text { Remote LNG production, LNG sea transport to north-western Europe import } \\
\text { terminals, distribution by truck/LNG trailer to skid-mounted LNG filling } \\
\text { stations. }\end{array}$ \\
\hline & $\mathrm{L}-\mathrm{CNG}$ & $\begin{array}{c}\mathrm{CNG} / \mathrm{LN} \\
\mathrm{G}\end{array}$ & $\begin{array}{l}\text { The same as LNG but at filling stations both LNG and CNG are available. } \\
\text { Also, includes LNG vaporisation/compression to CNG at skid-mounted L- } \\
\text { CNG. }\end{array}$ \\
\hline & LNG-STS & LNG & $\begin{array}{l}\text { Remote LNG production, LNG sea transport to north western Europe import } \\
\text { terminals, distributed by LNG bunkering vessel to bunkering facility at ports } \\
\text { (storage tank); ship-to-storage (STS). }\end{array}$ \\
\hline & LNG-TTS & LNG & $\begin{array}{l}\text { The same process description as LNG-STS, but LNG assumed to be distributed } \\
\text { by truck/LNG trailer to bunkering facility at ports (storage tank); truck-to- } \\
\text { storage (TTS). }\end{array}$ \\
\hline & LRNG-waste & LRNG & $\begin{array}{l}\text { Raw biogas production from waste, upgrading, liquefaction, and local } \\
\text { distribution by truck/LNG trailer to LNG filling stations. }\end{array}$ \\
\hline & LRNG-manure & LRNG & $\begin{array}{l}\text { Raw biogas production from manure, upgrading, liquefaction, and local } \\
\text { distribution by truck/LNG trailer to LNG filling stations. }\end{array}$ \\
\hline
\end{tabular}

The PIDF engine works on both diesel and gas; $50-60 \%$ gas (on energy basis) without compromising emissions. For maritime transport applications, due to the higher engine stroke to bore ratio, the share of gas could be as high as $95 \%$. The engine is usually optimised for gas operation and exhibits similar efficiency to conventional diesel engine (about 43\%) [12]. The HPDI gas engine works on the diesel cycle with $90-95 \%$ gas; a small amount of diesel is used to assist ignition to compromise NG's lower cetane number. As opposed to PISI and PIDF, where both CNG and LNG can be used, in a HPDI engine, only LNG is used, due to the required high pressure (about 300 bar) at the cylinder head. The assumed fuel economy for the medium size gasoline and $\mathrm{CNG}$ cars is $19 \mathrm{~km} / \mathrm{L}$ and $3.74 \mathrm{~kg} / 100 \mathrm{~km}$, respectively. For diesel cars, it was adjusted with the assumed engine cycle efficiencies. For HD vehicles, $31 \mathrm{~L} / 100 \mathrm{~km}$ and 28 $\mathrm{kg} / 100 \mathrm{~km}$ (for PISI engine), respectively. Also, for conventional passenger vessel to be $0.02 \mathrm{~km} / \mathrm{L}$; estimated with a capacity of 600 passengers cruising at 14 knots.

\section{Results and discussions}

Based on the assumptions discussed briefly in Section 2, the WTT costs of each selected pathway and the breakeven vehicle added costs for road transport and maritime transport applications have been investigated in detail, and the results are presented as follows.

\subsection{WTT fuel production and conditioning costs}

Figure 3 shows the fuel production and conditioning costs at each process stage, for each pathway. The gasoline and diesel fuel production costs are the average prices (excluding taxes) in Denmark in 2016, and used as a reference to compare the gas pathways. 


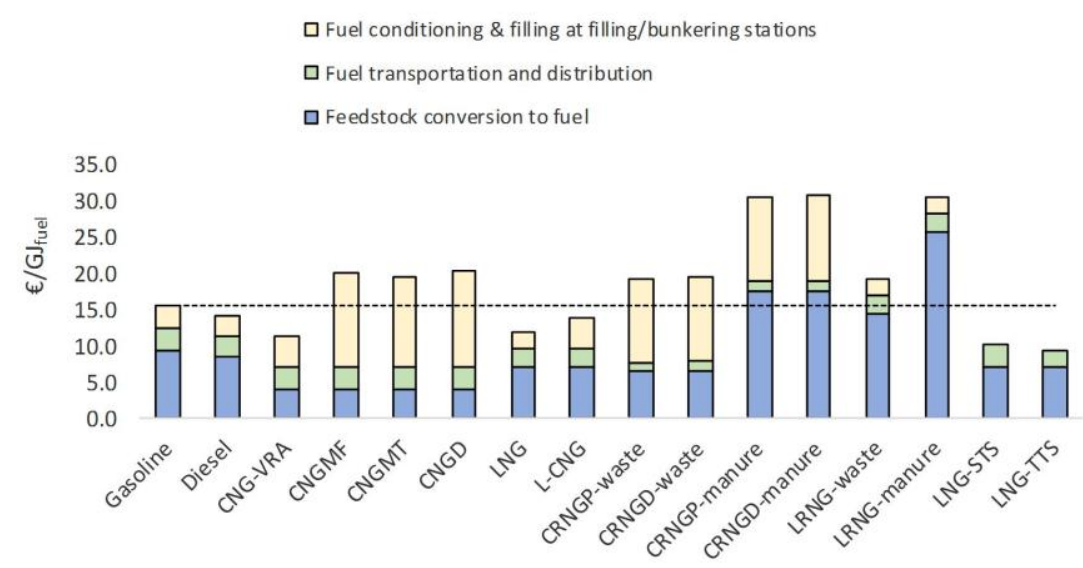

Figure 3. WTT fuel production and conditioning costs for all selected pathways. It also shows the cost break-down by process and activity.

As shown in figure 3, there exist substantial fuel production cost differences between CNG pathways, owing to the alternate gas transportation mechanism and filling station configuration: pipeline vs truck/trailer and fast-fill vs time-fill. CNG-VRA was found to be the cheapest pathway with an 11.2 €/GJ; however, all costs are to be transferred to private individuals, and affordability of the upfront investment cost is a challenge. Compared with the gasoline/diesel production cost, all CNG pathways, except CNG-VRA, showed marginal advantage. Despite its long-distance shipping $(10,000 \mathrm{~km})$ and distribution (via the GATE terminal to filling stations in Denmark, $1800 \mathrm{~km}$ round-trip distance), LNG/L-CNG pathways, on average, showed a 6.3 to $8.3 € / G J$ unit cost advantage over CNG pathways.

Owing to the high investment and upgrading costs, both CRNG-manure and waste pathways showed a higher unit cost over their counterparts, diesel/gasoline and CNG pathways (26.1 and $26.8 € / \mathrm{GJ}$, respectively). The subsequent upgrading and liquefication investment costs increase the overall unit cost of LRNG-manure and waste pathways further by more than $20 \%$. Comparing imported LNG with local liquefaction of biogas, the difference is quite substantial; it is not competitive over LNG, though it avoids the logistical problems in distribution and handling of the compressed biogas. It is worth nothing that, owing to the liquefaction cost of $8.14 € / \mathrm{GJ}$ (calculated for LRNG pathway) and fuel production cost $7.2 € / G J$ (calculated for CNGMF), small-scale LNG production would cost $15.34 € / \mathrm{GJ}$, which costs above imported LNG. Therefore, the choice between liquefying and not liquefying the upgraded gas relies on the tradeoff between the added $13 \%$ production cost and logistical advantages of liquefying biogas (LRNG).

It is also worth mentioning that, on average, filling station costs make up $50 \%$ of the total cost for all $\mathrm{CNG}$ pathways, but only $30 \%$ for LNG/L-CNG pathways, indicating that the handling costs of $\mathrm{LNG}$ are much lower than for $\mathrm{CNG}$.
In this study, bunkering costs at ports are assumed to be 'sunk' costs, as it is not the only activity going on at ports/harbours. Therefore, the unit cost of fuel supply excludes the bunkering cost. Thus, compared to roadtransport filling stations', both LNG-TTS and LNG-STS pathways have shown a lower cost. Comparing between LNG-TTS and LNG-STS, with the assumed $1,800 \mathrm{~km}$, round-trip distance and a $10 \mathrm{~m}^{3}$ daily demand per vessel, a trailer distribution was found to be the cheapest alterative over an LNG carrier, and hence, the LNG-TTS pathway showed a lower cost than LNG-STS

\subsection{Break-even vehicle added investment cost}

To analyse the trade-off between vehicle added cost and fuel price advantage or price gap, a lifecycle cost (LCC) comparison of gas vehicles with their corresponding counterparts, conventional vehicles, was made. It has three parts: (1) gasoline and diesel passenger cars vs PISI gas car; (2) HD diesel vehicle vs PISI, PIDF, and HPDI HD gas vehicles, and (3) LS-MGO passenger vessel vs PISI, PIDF, and HPDI HD LNG passenger vessels. The break-even added cost is the maximum vehicle added investment cost of a gas vehicle over its corresponding conventional vehicle at no-loss no-profit point, or zero NPV. For a given price gap and annual driving distance, the net benefit of a gas vehicle can be calculated by subtracting the market vehicle added cost from the breakeven vehicle added cost. Also, the price gap indicates the price difference between diesel/gasoline and CNG/LNG on energy basis.

\subsubsection{Passenger cars}

Figure 4 shows the break-even added cost of gas cars over gasoline and diesel passenger cars. Evaluating the current performance of gas cars over gasoline cars, the break-even added cost at $0.33 € / \mathrm{L}$ price gap $(1.4 € / \mathrm{L}$ 


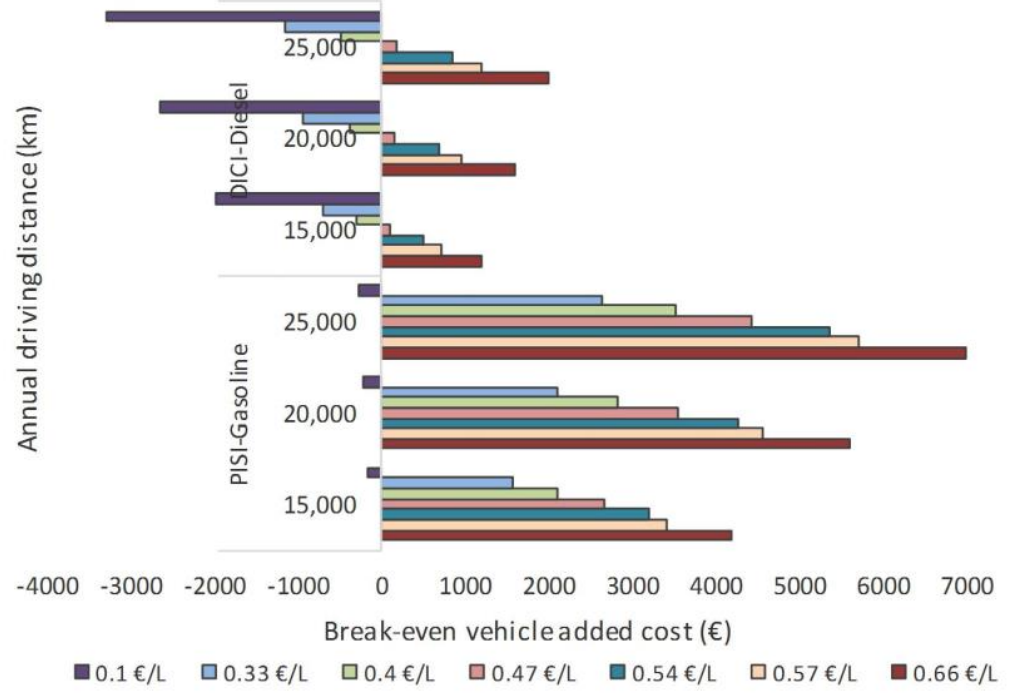

Figure 4. Break-even vehicle added cost of gas car for varied price gap and annual driving distance.

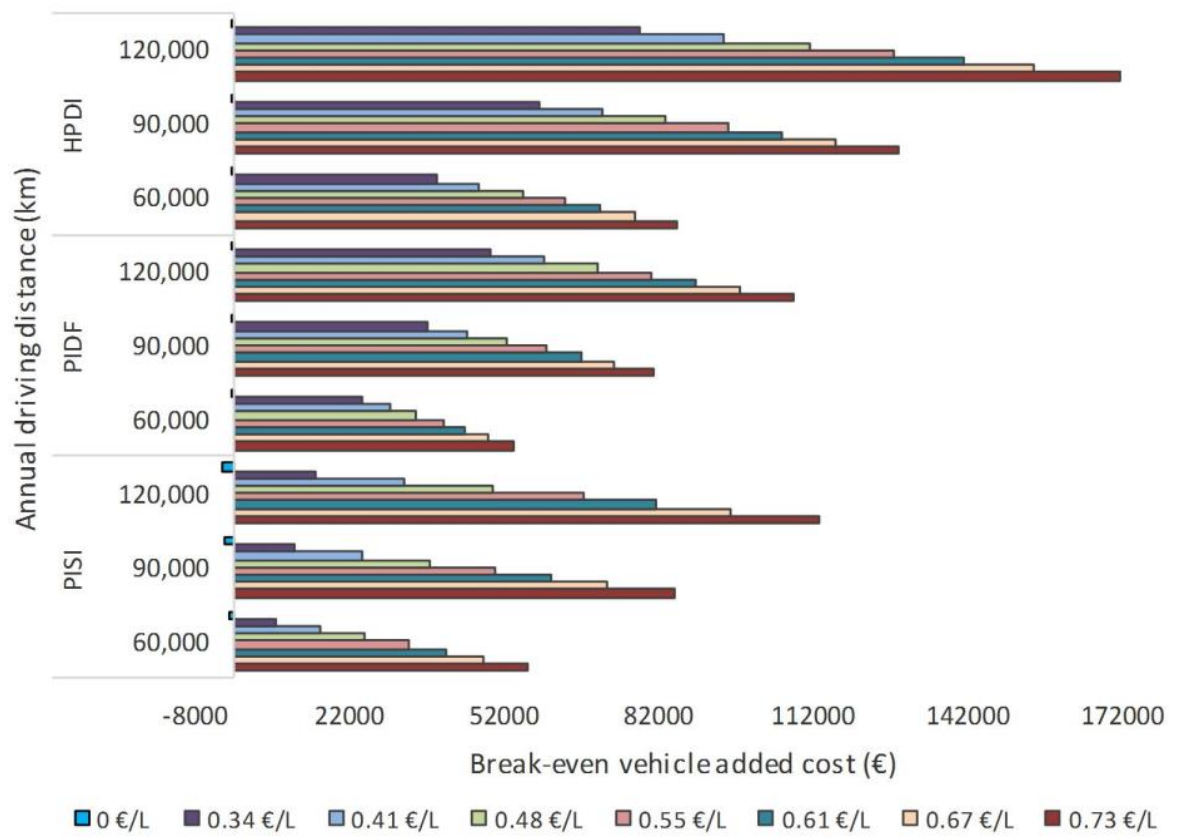

Figure 5. Break-even vehicle added cost of HD gas vehicle for varied price gap and annual driving distance. The price gap indicates the price advantage of $\mathrm{LNG} / \mathrm{CNG}$ over diesel. The assumed current market prices at filling stations are: diesel (1.17 €/L), CNG (1.6 $€ / \mathrm{kg})$, and $\mathrm{LNG}(1.03 € / \mathrm{kg})$.

gasoline and $1.6 € / \mathrm{kg} \mathrm{CNG}$ price in Denmark) is estimated to be $1,585,2,113$, and $2,642 €$ for an annual driving distance of $15,000,20,000$, and $25000 \mathrm{~km}$, respectively. This means that, to be profitable, the current market added cost of gas cars should be less than the estimated break-even costs. For example, as of June 2017, the highest selling gas car in Sweden, the VW 1.4 TGI 110 BlueMotion, has an added cost of $1630 €[13]$. In [11], the average added cost is reported to be between $700-1,050 €$. The saving of VW 1.4 TGI 110 BlueMotion, in our case, would only be 483 and $1,012 €$ if the annual driving distance is 20,000 and $25,000 \mathrm{~km}$, respectively.
Since, in most cases, the average annual driving distance of a passenger car is below $15,000 \mathrm{~km}-11,037 \mathrm{~km}$ in Denmark, $12,240 \mathrm{~km}$ in Sweden, $12,387 \mathrm{~km}$ in Norway increasing the price gap is a more realistic way should gas cars be of interest. It is also important to note that the break-even added cost is marginally more sensitive to gasoline price than $\mathrm{CNG}$ price. For example, a $10 \%$ reduction in $\mathrm{CNG}$ price would increase the price gap to $0.44 € / \mathrm{L}$ while a $10 \%$ increase in gasoline price would result in $0.47 € / \mathrm{L}$. 


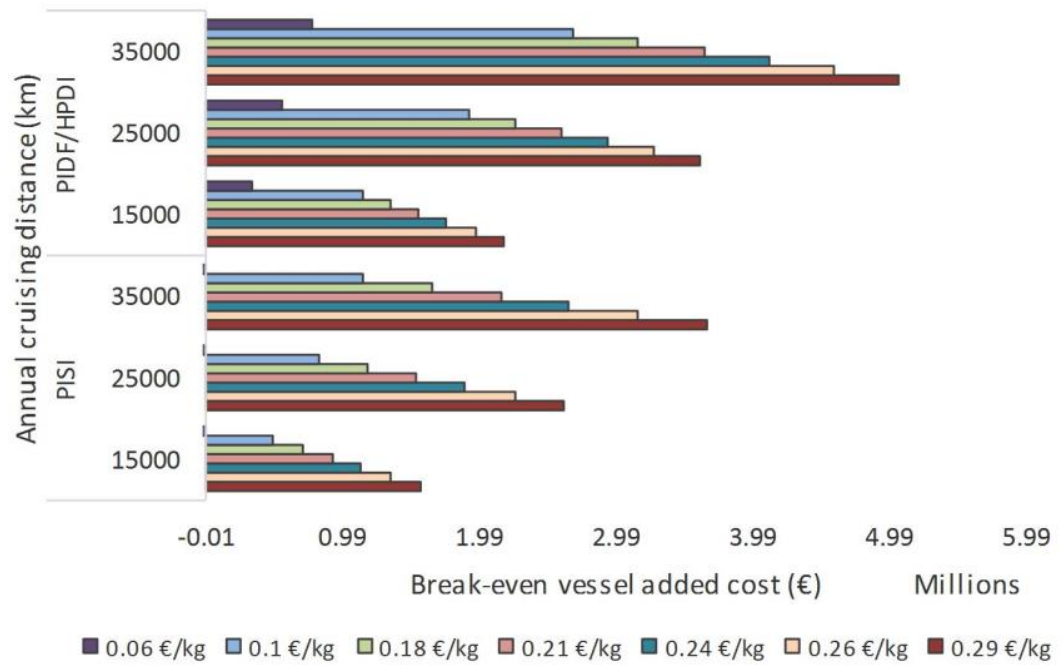

Figure 6. Break-even added cost of LNG passenger vessels for varied price gap and annual cruising distance. The price gap indicates the price advantage of LNG over LS-MGO, in terms of $€ / \mathrm{kg}$ of LS-MGO. The assumed current market prices at ports are: LS-MGO $(0.51 € / \mathrm{kg})$ and $\mathrm{LNG}(0.48 € / \mathrm{kg})$.

Compared to gasoline, diesel is cheaper, at $1.17 € / \mathrm{L}$, and with the current $1.6 € / \mathrm{kg}$ CNG price, the price gap is zero. As seen in figure 4, there is a substantial difference between the gasoline and diesel car cases. Conventional diesel cars are more efficient than gasoline cars. The lower price gap and increased fuel economy contributes to the negative break-even added cost. Negative breakeven added cost indicates a net loss. Even at a $0.66 € / \mathrm{L}$ price gap (corresponding to a $1.83 € / \mathrm{L}$ diesel price) the break-even added cost is only $1,200 €$ at $15,000 \mathrm{~km}$, while the cost increases to $2,000 €$ at $25,000 \mathrm{~km}$. Normally, for similar brake power output, diesel cars are more expensive than gasoline cars by about 2,000 $€$ [13], and comparing a diesel with a gas car would be an even more expensive option.

\subsubsection{Heavy duty vehicles}

Figure 5 shows the comparison made for HD diesel and gas vehicles. Three cases are drawn for the HD gas vehicle: PISI, PIDF, and HPDI engine. CNG is the only fuel used in PISI while LNG is used in both PIDF and HPDI engines. Technically, both $\mathrm{CNG} / \mathrm{LNG}$ could be used in a PIDF engine. The effect of higher fuel consumption and longer driving distance in HDVs on the break-even added cost can be noted by comparing figure 4 and figure 5. For the same price gap, the break-even added cost is significantly higher in the HDV application. Evaluating the current performance of the PISI engine $\mathrm{HD}$ vehicle, the price gap is zero $(1.17 € / \mathrm{L}$ and $1.6 € / \mathrm{kg})$, which results in negative break-even cost at all driving distances: $-1,216,-1,823$, and $-2,430 €$ at $60,000,90,000$ and $120,000 \mathrm{~km}$, respectively. On average, the added cost for $\mathrm{HD}$ gas vehicles is reported to be between 10,600$16,450 €[11]$; assuming this, for PISI-engine profitability, a price gap higher than $0.34 € / \mathrm{L}$ or $29 \%$ reduction in CNG price is required at $60,000 \mathrm{~km}$. LNG is much cheaper than $\mathrm{CNG}$; the current price gap is about 0.42 $€ / \mathrm{L}$. Evaluating the current performance, the break-even cost is estimated to be 30,000 and $47580 €$ for PIDF and HPDI engine vehicles, respectively, at $60,000 \mathrm{~km}$. On average, for both engines, the break-even cost increases by $50 \%$ and $100 \%$ at $90,000 \mathrm{~km}$ and $120,000 \mathrm{~km}$, respectively. Most refuse trucks and city buses travel less than $60,000 \mathrm{~km}$ per annum while long-haul truck/trailers travel more than $100,000 \mathrm{~km}$. For example, in Sweden, the average annual driving distance of a bus is about $56,960 \mathrm{~km}$ [14]. A HPDI gas engine vehicle would be, economically, more competitive in long-haul transport application owing to the higher diesel fuel substitution rate. The added cost of HPDI is normally higher than PIDF due to new accessories (like on-board high-pressure fuel pump), but the higher break-even cost could potentially outweigh the added cost benefit of PIDF.

A comparison of our results with prior studies shows that the results are in line with [15], though it shows the estimated break-even distance (annual traffic volume) instead of added vehicle cost (the other way round). For a $0.45 € / \mathrm{L}$ price gap and 42,000-50,000 $€$ added vehicle cost, the break-even distance was estimated to be 123,000, 360,000 , and $456,000 \mathrm{~km}$ for refuse trucks (CNG), transit buses (CNG), and long-haul fright trucks (LNG), respectively. The correlation between price gap and break-even distance was found to be a gently decreasing exponential function.

\subsubsection{Passenger vessels}

Figure 6 shows the break-even cost of LNG vessels cruising in Emission Control Areas; in relation with LSMGO passenger vessel. Since, for maritime transport applications, the share of gas substitution in PIDF is above $95 \%$, there is no distinction between the PIDF and HPDI cases here. The results indicate that a minimum of $0.1 € / \mathrm{kg}$ is required to break-even at the assumed 
minimum annual cruising distance. For the assumed highest annual cruising distance $(35,000 \mathrm{~km})$ and highest price gap $(0.29 € / \mathrm{kg})$, the break-even costs estimated to be as high as $5 \mathrm{M} €$ and $3.67 \mathrm{M} €$ for PIDF/HPDI and PISI LNG vessels, respectively. Potentially, the break-even cost shows the cost advantage between installing sulphur scrubber and swapping for high quality fuels like LNG. Owing to the higher fuel consumption of maritime transport per $\mathrm{km}$ travel, in general, for high frequency and short distance routes, as most ferries in Denmark, swapping the existing ferries for LNG is advantageous over LS-MGO.

\section{Conclusions}

In this study, 14 potential gas supply pathways were evaluated for road transport and maritime transport applications through WTT fuel production costs evaluation and break-even added investment costs of NGVs. The pathways are evaluated in the Danish gas (natural/biogas) context.

The results indicate that the gas distribution mode and filling stations configuration largely impact the WTT fuel production costs of the selected gas pathways; in most cases, filling station costs alone make up $50 \%$ of the total costs in all CNG pathways and $30 \%$ in all LNG/L-CNG pathways. The large economy of scale outweighs the long-distance shipping and distribution costs of imported LNG, and showed the least-cost of all gas and diesel/gasoline pathways. Due to the high investment costs, the choice between liquefying and not liquefying the upgraded biogas relies on the trade-offs between the added production costs and logistical advantages of liquefying biogas. The price gaps and annual driving distances are critical for gas vehicles cost competitiveness. For a given price gap, the higher the annual fuel consumption, the higher would be the annual savings and the break-even added investment costs of gas vehicles. Lastly, the results, however, are very sensitive to the various critical assumptions that made throughout this paper, such as, the investment costs, gas distribution distances, and others. Hence, the results should be interpreted with that in mind.

\section{Acknowledgments}

The authors are grateful for the financial support from the Innovation Fund Denmark under the FutureGas project.

\section{References}

1. European Enviromental Agency. Transport greenhouse gas emissions. 2017 [cited 2017
February 16]; Available from: http://www.eea.europa.eu/airs/2016/resourceefficiency-and-low-carbon-economy/transport-ghgemissions.

2. International Association for Natural Gas Vehicles (IANGV). Latest International NGV Statistics. 2016; Available from: http://www.iangv.org/.

3. NGV Global. Natural Gas Vehicles by country. 2016 [cited 2016 December 22]; Available from: http://www.iangv.org/stats/NGV Global Stats1.htm.

4. International Maritime Organization (IMO). Sulphur oxides (SOx) - Regulation 14. 2016 [cited 2017 January 04]; Available from: http://www.imo.org/en/OurWork/Environment/Pollut ionPrevention/AirPollution/Pages/Sulphur-oxides(SOx)-\%E2\%80\%93-Regulation-14.aspx.

5. Eise Fokkema, J., P. Buijs, and I.F.A. Vis, An investment appraisal method to compare LNG-fueled and conventional vessels. Transportation Research Part D: Transport and Environment, 2017. 56: p. 229240.

6. H2A Analysis Group. H2A Delivery Components Model version 2.0. 2017 [cited 2017 May 29]; Available from: https://www.hydrogen.energy.gov/h2a_analysis.html.

7. ENERGINET.DK, Technology data for energy plants. 2012: Denmark. p. 157.

8. Bauer, F., et al., Biogas upgrading - Review of commercial technologies. 2013, Swedish Gas Centre (SGC).

9. Stolt-Nielsen Limited. 2017 [cited 2017 August 12]; Available from: https://www.stoltnielsen.com/en/press-release/ $\mathrm{id}=566$.

10. Smith, M. and J. Gonzales, Costs Associated With Compressed Natural Gas Vehicle Fueling Infrastructure. 2014: Denver, USA. p. 15.

11. Kollamthodi, S., et al., The role of natural gas and biomethane in the transport sector 2016, Ricardo Energy \& Environment United Kingdom

12. Hegab, A., A. La Rocca, and P. Shayler, Towards keeping diesel fuel supply and demand in balance: Dual-fuelling of diesel engines with natural gas. Renewable and Sustainable Energy Reviews, 2017. 70(Supplement C): p. 666-697.

13. Volkswagen (VW) Sweden. Price list. 2017 [cited 2017 August 30]; Available from: https://www.volkswagen.se/sv/broschyrer.html.

14. SIKA, Values and methods of the transport sector socioeconomic analysis. 2009: Östersund, Sweden. p. 122.

15. Cai, H., et al., Wells to wheels: Environmental implications of natural gas as a transportation fuel. Energy Policy, 2017. 109: p. 565-578. 